\title{
Optimization of Heating Process for Bearing Rings in a Vacuum Furnace Based on Numerical Analysis
}

\author{
Jing LIU, Jiadong LI, ${ }^{*}$ Zhaodong WANG, Yong TIAN and Haojie WANG \\ The State Key Laboratory of Rolling and Automation, Northeastern University, NO. 3-11, Wenhua Road, Heping District, \\ Shenyang, P. R. China.
}

(Received on August 2, 2020; accepted on August 20, 2020)

\begin{abstract}
With the aid of a FEM software COMSOL Multiphysics the transient radiation heat transfer model has been established to simulate the vacuum heating process of M50NiL bearing rings. The heating curves obtained from the numerical model compare well with the experimental data. Based on the model, effects of heating process parameters on the radiative heat transfer in a vacuum furnace are investigated. The simulation results indicate that reducing heating rate or increasing preheating temperature can improve the temperature uniformity, thereby reducing the soaking time of bearing rings. Accordingly, an optimized heating process with high preheating temperature and low heating rate is proposed. The new process cuts the soaking time by a quarter and reduces the proportion of grade 3 and coarser grains from $12 \%$ to $2 \%$.
\end{abstract}

KEY WORDS: numerical analysis; vacuum heating; temperature uniformity; soaking time; bearing ring.

\section{Introduction}

The M50NiL bearing steel is designed for the new generation of gas turbine engines. In order to serve at high temperature and high rotate speed, it usually requires surface strengthening treatment to obtain high hardness and wear resistance, while maintaining the good impact toughness and fracture toughness of the core. ${ }^{1,2)}$ Carburizing and quenching are commonly used for improving fraction and fatigue properties of high-speed bearings. The components first need to be heated above critical temperature for austenization. But with long time high temperature heat treatment, the austenite grain size of M50NiL steel is difficult to control. ${ }^{3)}$ The increase of heating temperature and the extension of soaking time will cause the growth of austenite grains of M50NiL steel. Especially when the heating temperature is higher than $1100^{\circ} \mathrm{C}$, since the second phase particles begin to dissolve and the pinning effect weakens, the austenite grains will grow quickly. ${ }^{4,5)}$ Coarse austenite grain is not conductive to the improvement of mechanical properties. Qiu et $a l .{ }^{6)}$ investigated the influence of grain size on the ductile fracture toughness of ferrite steel and found that grain coarsening increases crack tip opening displacement and the possibility of cleavage fracture. Fine grain size can promote a somewhat greater shock resistance and have a less tendency to crack. ${ }^{7)}$ Liu et al. ${ }^{8}$ reported that large grain size microstructure shows higher crack propagation

\footnotetext{
* Corresponding author: E-mail: lijd@mail.neu.edu.cn
}

rate than small grain microstructure in IN713C nickel-based superalloy. Therefore, in order to produce high quality bearing rings for aeroengine, the heating process should be optimized to avoid excessive grain growth.

Heat treating metal in a vacuum furnace can avoid oxidation and decarburization to attain bright surfaces. ${ }^{9,10}$ ) Moreover, the heating rate and holding time in the vacuum heating chamber can be automatically controlled. Thus, vacuum heat-treating technology has been widely applied in aeroengine superalloy. ${ }^{11,12)}$ A typical vacuum heating process consists of three consecutive stages: heating up stage, temperature homogenization stage and austenization stage. The heating up time is determined by the heating rate, which can be precisely controlled by the PID controller of the furnace; the homogenization time is determined by the heating rate, heating temperature, parts shape and load capacity; austenization time is determined by the material properties. ${ }^{13)}$ As the austenitizing temperature is fixed, the excessive growth of grains can only be avoided by shortening the holding time. Therefore, it is of great significance to analyse the temperature uniformity of workpieces in the heating furnace.

Over the past few decades, computer simulation technology has become an effective tool for the investigation of the heat transfer problem. Many numerical methods have been developed to solve radiative transfer equation, such as Monte Carlo (MCM), zonal, Spherical Harmonics $\left(\mathrm{P}_{\mathrm{N}}\right)$, discrete ordinates (DOM), discrete transfer (DTM), meshless, finite element (FEM) and finite volume (FVM). ${ }^{14)}$ Sun 
et al. ${ }^{15,16)}$ compared the performance of the $\mathrm{P}_{\mathrm{N}}$ method, the simplified $\mathrm{P}_{\mathrm{N}}$ method $\left(\mathrm{SP}_{\mathrm{N}}\right), \mathrm{FVM}$, lattice Boltzmann method (LBM) and the DOM to solve transient conduction and radiation heat transfer problems. According to their research, FVM is recommended for optical thickness $\tau \leq 5$, and P1 for $\tau=10,50$. Borjini et al. ${ }^{17)}$ developed the FVM with blocked-off-region procedure to solve the radiative heat transfer problem in a partitioned idealized furnace with a finite-thickness opaque partition. Lari et al. ${ }^{18)}$ and Mayr et $a l .{ }^{19)}$ used the DOM for the solution of radiative heat transfer in the furnace with participating media. The FEM coupled with electromagnetic field and heat conduction analysis is employed to optimize the induction heating of a bearing raceway by Yuki. ${ }^{20)}$ Now instead of writing code, matured commercial software has become the preferred solution of coupled heat transfer problems. FLUENT software is used for the simulation of heating process in the reheating furnace by Gu et $a .^{21)}$ and Liu et al. ${ }^{22)}$ Ramezanzadeh et al. ${ }^{23)}$ developed a two-phase flow solver based on the OpenFOAM CFD software to simulate the forced convection quenching process. Dong and $\mathrm{Liu}^{24)}$ carry out the multi-objective optimization design of microchannel with fixed solid heat sources based on the COMSOL Multiphysics. Tikal et al. ${ }^{25)}$ explored the impact factors on cracks forming during soaking of ingots in heating forging furnace with the aid of two FEM software. These above kinds of simulation software have their advantages for different application fields. COMSOL Multiphysics offers the users various physics interfaces including fluid flow and heat transfer and multiple choices of element types, meshing procedures and solver types. ${ }^{26)}$

In this paper, the FEM software COMSOL Multiphysics is used to calculate the $3 \mathrm{D}$ transient temperature field of bearing rings in the vacuum furnace. And the veracity of the prediction temperature is verified by the experimental results. Based on the model, effects of heating rate and preheating temperature on the vacuum heating process are discussed. An optimized heating process is proposed to avoid excessive grain growth.

\section{Model Description}

\subsection{Geometric Model and Material Properties}

Ipsen's single-chamber gas quench furnace and eighteen bearing rings of M50NiL steel are used in the present study. The schematic of the heating chamber after loading and the dimensions of bearing ring and graphite heating tube are shown in Fig. 1. The temperature uniformity of the heating zone is within $\pm 5^{\circ} \mathrm{C}$.

Table 1 lists the thermophysical properties of the graphite felt, the graphite heating tube, the heat-treating tray and the bearing ring. The thermal conductivity and specific heat of M50NiL steel related to temperature were calculated with the help of JMatPro software, as shown in Fig. 2.

\subsection{Governing Equations}

The commercial FEM software COMSOL Multiphysics version 5.4 is applied to solve the governing equations. ${ }^{27)}$ As absolute pressure of the nitrogen atmosphere is only about $1 \mathrm{~Pa}$, thermal convection can be neglected. The energy conservation equations for solid are given as:

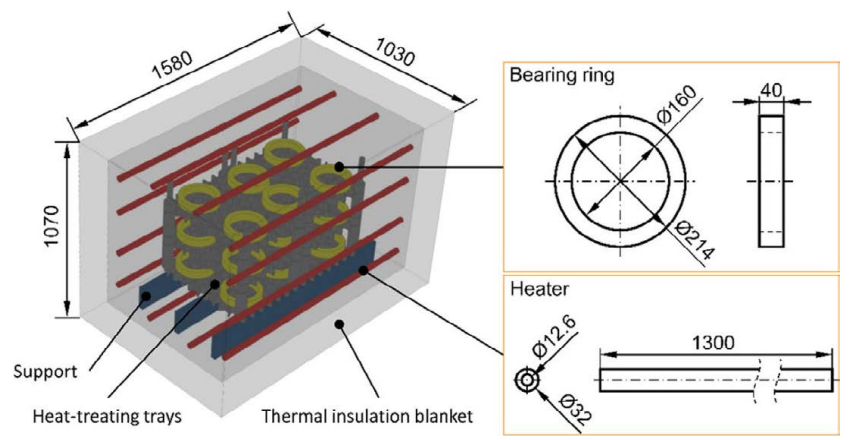

Fig. 1. Geometry and dimensions of the heating chamber and bearing rings. (Online version in color.)

Table 1. Thermophysical properties.

\begin{tabular}{cccccc}
\hline Component & Material & $\rho, \mathrm{kg} / \mathrm{m}^{3}$ & $k, \mathrm{~W} /(\mathrm{m} \cdot \mathrm{K})$ & $c_{p}, \mathrm{~J} /(\mathrm{kg} \cdot \mathrm{K})$ & $\varepsilon$ \\
\hline insulation & graphite felt & 120 & 0.35 & 350 & 0.77 \\
heater & graphite & 1700 & 180 & 1850 & 0.95 \\
$\begin{array}{c}\text { heat-treating } \\
\text { tray }\end{array}$ & $\begin{array}{c}\text { Cr26Ni18Mo } \\
\text { steel }\end{array}$ & 7670 & 24 & 700 & \\
bearing rings & M50NiL steel & 7820 & - & - & 0.66 \\
\hline
\end{tabular}

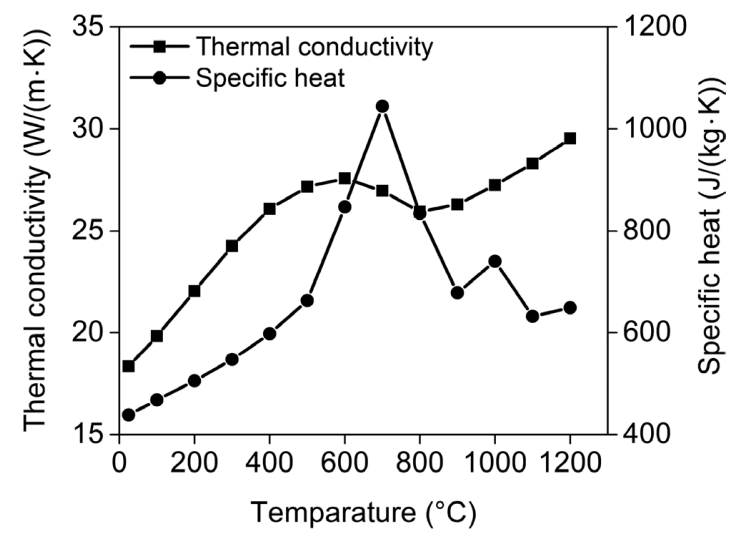

Fig. 2. Thermo-physical properties of M50NiL steel related to the temperature.

$$
\begin{array}{r}
\rho c_{p}\left(\frac{\partial T}{\partial t}+\mathbf{u}_{\text {trans }} \cdot \nabla T\right)+\nabla \cdot\left(\mathbf{q}+\mathbf{q}_{r}\right)=-\alpha \mathrm{T}: \frac{d S}{d t}+Q . \\
\mathbf{q}=-\lambda \nabla T \ldots \ldots \ldots \ldots \ldots \ldots \ldots \ldots \ldots \ldots \ldots \ldots \ldots \ldots \ldots \ldots \ldots \ldots
\end{array}
$$

where $\rho$ is the solid density, $c_{\mathrm{p}}$ is the specific heat capacity, $T$ is the absolute temperature, $t$ is the time, $\mathbf{u}_{\text {trans }}$ is the velocity vector of translational motion, $\lambda$ is the thermal conductivity, $\mathbf{q}_{\mathrm{r}}$ is the radiative heat flux, $\alpha$ is the coefficient of thermal expansion, $S$ is the second Piola-Kirchhoff stress tensor, $Q$ is the heat source.

In vacuum environment, thermal radiation is a heat transfer mode that must be considered for heating. The net inward radiative heat flux $q_{\mathrm{r}}$ at the solid surface is given by the difference between the irradiation and radiosity:

$$
\begin{array}{r}
q_{r}=G-J \\
G=G_{\mathrm{m}}+\sum F_{\mathrm{ext}} P_{\mathrm{s}}+\sum F_{\mathrm{ext}} q_{0, \mathrm{~s}}+F_{\mathrm{amb}} e_{\mathrm{b}}\left(T_{\mathrm{amb}}\right) \ldots \\
J=\rho G+\varepsilon e_{\mathrm{b}}(T)
\end{array}
$$




$$
e_{\mathrm{b}}(T)=n^{2} \sigma T^{4}
$$

where $G_{\mathrm{m}}$ is mutual irradiation between different boundaries, $F$ is the view factor, $P_{\mathrm{s}}$ is the sum gathers radiation sources located on a point, $q_{0}, \mathrm{~s}$ is the directional radiative sources, $\varepsilon$ is the surface emissivity, $n$ is the refractive index, $\sigma$ is the Stefan-Boltzmann constant.

In this model, Hemi-cube algorithm is used to evaluate the surface to surface radiation. Consider a point $\mathrm{P}$ on a surface $S$, which can be seen by points on other surfaces such as $S^{\prime}$, as well as the ambient surrounding, $S_{\text {amb. Assume }}$ that the point $\mathrm{P}^{\prime}$ on $S^{\prime}$ have a local radiosity, $J^{\prime}$, while the ambient surrounding has a constant temperature, $T_{\mathrm{amb}}$. The mutual irradiation $G_{\mathrm{m}}$ at point $\mathrm{P}$ is given by the following surface integral:

$$
G_{\mathrm{m}}=\int_{S^{\prime}} \frac{\left(-\mathbf{n}^{\prime} \cdot \mathbf{r}\right)(\mathbf{n} \cdot \mathbf{r})}{\pi|\mathbf{r}|^{4}} J^{\prime} d s
$$

where $\mathbf{n}$ and $\mathbf{n}^{\prime}$ is the normal vector at point $\mathrm{P}$ and $\mathrm{P}^{\prime}, \mathbf{r}$ is the vector from $\mathrm{P}$ to $\mathrm{P}^{\prime}$.

The ambient view factor, $F_{\mathrm{amb}}$, is determined from the integral of the surrounding surfaces $S^{\prime}$, here denoted as $F^{\prime}$ :

$$
F_{\mathrm{amb}}=1-F^{\prime}=1-\int_{S^{\prime}} \frac{\left(-\mathbf{n}^{\prime} \cdot \mathbf{r}\right)(\mathbf{n} \cdot \mathbf{r})}{\pi|\mathbf{r}|^{4}} d s
$$

The heat source $Q$ is specified as the electric power $P_{\mathrm{h}}$ per unit volume of graphite heating tubes, and $P_{\mathrm{h}}$ is calculated by PID controlled algorithm:

$$
\begin{array}{r}
Q=P_{\mathrm{h}} / V_{\mathrm{h}} \\
P_{\mathrm{h}}=k_{\mathrm{P}} e_{T}(t)+k_{\mathrm{I}} \int_{0}^{t} e_{\mathrm{T}}(t) d t+k_{\mathrm{D}} \frac{d e_{\mathrm{T}}(t)}{d t}
\end{array}
$$

where $e_{T}$ is the deviation between simulated and designed furnace temperature.

It should be noted that the following simulations are performed on a computer with two Intel Xeon E5-2680 v2 $2.80 \mathrm{GHz}$ and $128 \mathrm{~GB}$ of RAM.

\subsection{Grid Independence Test}

Because of the symmetry of the heating chamber, the computational domain is simplified to a quarter of the real model as shown in Fig. 3, where the symmetry plane is displayed in blue. The unstructured grids were generated in the solid domain. Before performing systematic numerical calculations, grid independence test was conducted to achieve the balance between the computational accuracy and efficiency. The furnace temperature after heating $30 \mathrm{~min}$ at a constant power of $40 \mathrm{~kW}$ was compared in the test. As listed in Table 2, when decreasing the grid size from coarse to normal, the relative error of the furnace temperature decreased from $3.1 \%$ to $0.01 \%$. When increasing the grid number from 25801 to 37759 , the relative error is reduced only by $0.01 \%$, but the calculation time is tripled. Therefore, the normal-size grid is adopted in this study.

\subsection{Model Validation}

The heating experiment was performed to validate the reliability of the numerical model. The picture of experi-

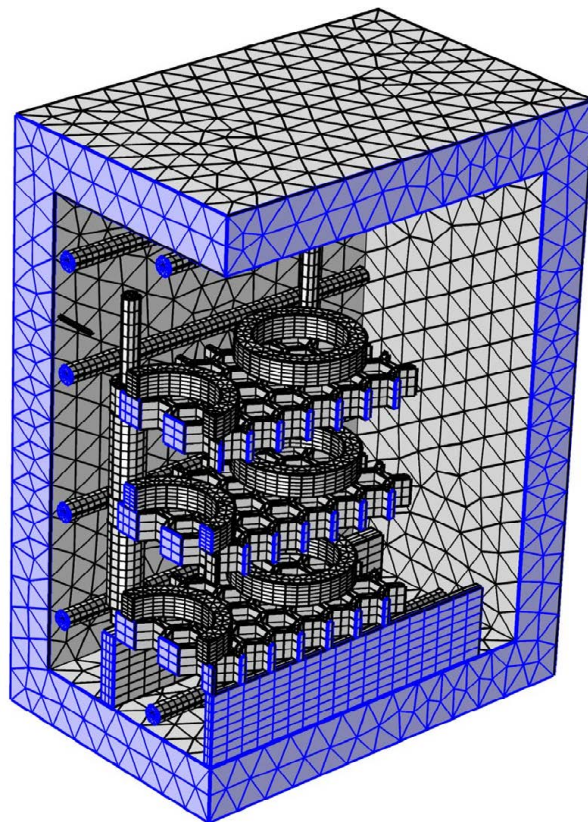

Fig. 3. Computational domain of finite element analysis. (Online version in color.)

Table 2. Grid independence analysis

\begin{tabular}{cccc}
\hline Grid size & $T_{30} /{ }^{\circ} \mathrm{C}$ & Relative error $\delta / \%$ & Calculate time t $/ \mathrm{s}$ \\
\hline Coarse (14 678) & 659.2 & $-3.1 \%$ & $16 \mathrm{~h} 4 \mathrm{~min} 54 \mathrm{~s}$ \\
Normal (25 801) & 680.2 & $-0.01 \%$ & $31 \mathrm{~h} 55 \mathrm{~min} 3 \mathrm{~s}$ \\
Fine (37 759) & 680.3 & - & $99 \mathrm{~h} 2 \mathrm{~min} 45 \mathrm{~s}$ \\
\hline
\end{tabular}

mental system is presented in Fig. 4, which consists of a vacuum furnace, bearing rings, thermocouples, and a data acquisition system. Nine of the eighteen bearing rings were drilled the hole with a diameter of $3 \mathrm{~mm}$ and a depth of 20 $\mathrm{mm}$ respectively. 3-mm type $\mathrm{N}$ thermocouples were inserted into the holes to measure the central temperature of the bearing rings. And the thermocouple temperature data was collected by Agilent 34970A data acquisition every two minutes.

Figure 5 illustrates the complete process of actual highpressure gas quenching treatment. However, only the hightemperature vacuum heating stage is studied by numerical simulation method. The low- temperature convection preheating stage and the forced convection cooling stage are not considered in this study, as they have little effect on grain size. But the quenching process can significantly affect product mechanics. So the complex interaction of quenching medium fluid field with temperature field, microstructure field and stress field is a topic for further research.

The comparison between numerical and experimental values of top corner temperature $T 1$ (241, 170, 1147$)$, bottom corner temperature $T 2(26.5,-30,790)$ and the centre temperature $T 3(241,-230,1147)$ are illustrated in Fig. 6. It can be seen that the calculated temperature is in good agreement with the measured one, and the maximum absolute error is less than $0.6 \%$. The results show the reliability and accuracy of the simulation model. It can be used for predicting the temperature field of bearing rings during vacuum heating. 

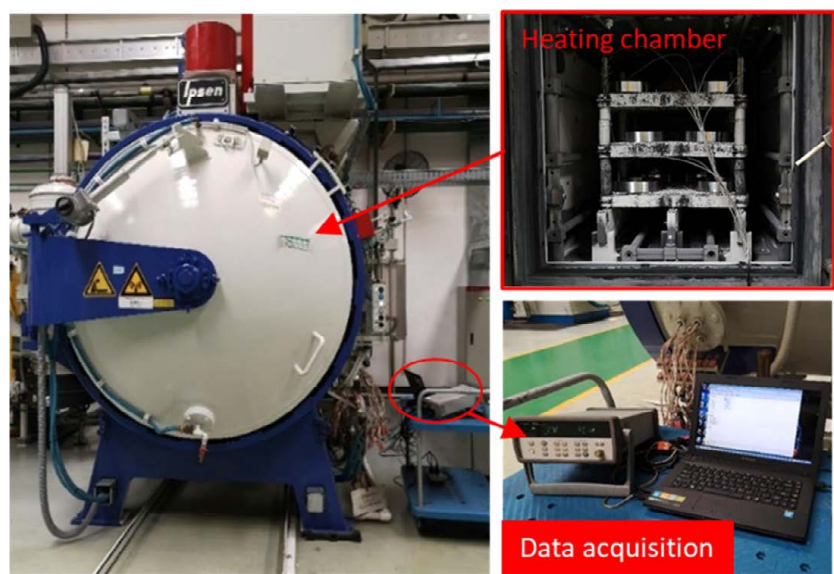

Fig. 4. Loaded vacuum furnace and the temperature recording system. (Online version in color.)

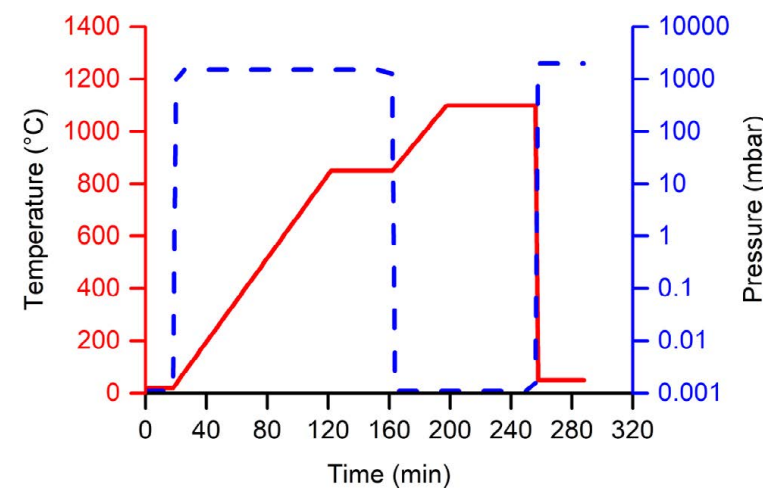

Fig. 5. The complete high-pressure gas quenching process. (Online version in color.)

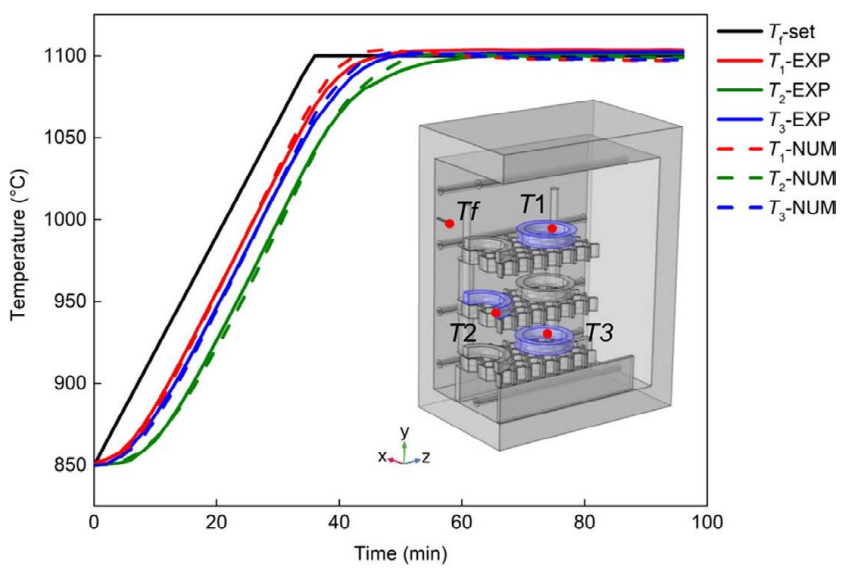

Fig. 6. Comparison of the experimental and numerical temperature rise curves. (Online version in color.)

\section{Results and Discussion}

\subsection{Effect of Heating Rate}

In this section, the influence of heating rate on the heating characteristics of bearing rings is studied. The simulation parameters and the required CPU time $t_{\mathrm{CPU}}$ for different conditions are listed in Table $\mathbf{3}$.

The holding time of vacuum heat treatment is composed of two parts: one is the temperature equalization time (also called soaking time), the other is the austenitizing time. ${ }^{28)}$ When the furnace temperature reaches the set value, it starts to enter the soaking stage, and the start time is denoted by
Table 3. Simulation parameters and required CPU time for different conditions.

\begin{tabular}{ccccccccc}
\hline Case & $\begin{array}{c}T_{0}, \\
{ }^{\circ} \mathrm{C}\end{array}$ & $\begin{array}{c}v_{\mathrm{p}}, \\
{ }^{\circ} \mathrm{C} / \mathrm{min}\end{array}$ & $\begin{array}{c}T_{\mathrm{p}}, \\
{ }^{\circ} \mathrm{C}\end{array}$ & $\begin{array}{c}t_{\mathrm{p}}, \\
\mathrm{min}\end{array}$ & $\begin{array}{c}v_{\mathrm{h}}, \\
{ }^{\circ} \mathrm{C} / \mathrm{min}\end{array}$ & $\begin{array}{c}T_{\mathrm{h}}, \\
{ }^{\circ} \mathrm{C}\end{array}$ & $\begin{array}{c}t_{\mathrm{h}}, \\
\mathrm{min}\end{array}$ & $t_{\mathrm{CPU}}$ \\
\hline Case1 & 850 & - & - & - & 4 & 1100 & 40 & $49 \mathrm{~h} 49 \mathrm{~min} 34 \mathrm{~s}$ \\
Case2 & 850 & - & - & - & 7 & 1100 & 40 & $31 \mathrm{~h} 55 \mathrm{~min} 3 \mathrm{~s}$ \\
Case3 & 850 & - & - & - & 10 & 1100 & 40 & $29 \mathrm{~h} 19 \mathrm{~min} 53 \mathrm{~s}$ \\
Case4 & 850 & 7 & 950 & 30 & 7 & 1100 & 40 & $78 \mathrm{~h} 57 \mathrm{~min} 48 \mathrm{~s}$ \\
Case5 & 850 & 7 & 1000 & 30 & 7 & 1100 & 40 & $72 \mathrm{~h} 55 \mathrm{~min} 21 \mathrm{~s}$ \\
Case6 & 850 & 7 & 1050 & 30 & 7 & 1100 & 40 & $80 \mathrm{~h} 5 \mathrm{~min} 36 \mathrm{~s}$ \\
\hline
\end{tabular}

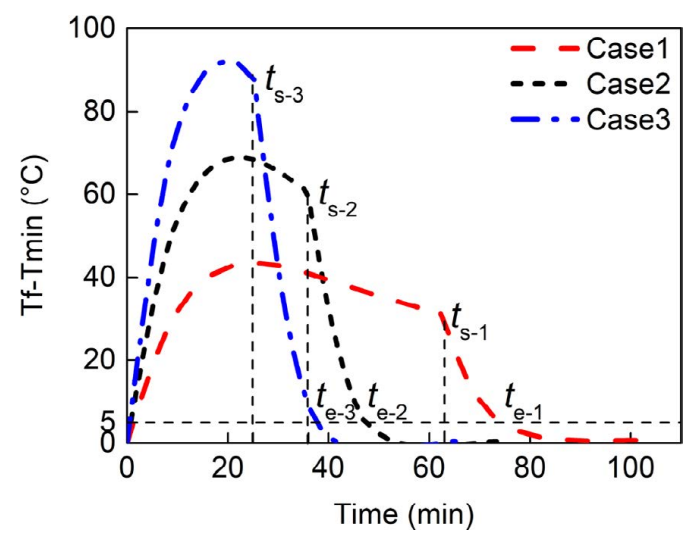

Fig. 7. Temperature difference between the bearing ring and the furnace under different heating rates. (Online version in color.)

$t_{\mathrm{s}}$; when the temperature difference between the workpieces and the furnace is less than $5^{\circ} \mathrm{C}$, the soaking stage is over, and the end time is denoted by $t_{\mathrm{e}}$. So, the total soaking time is equal to $t_{\mathrm{e}}-t_{\mathrm{s}}$. Figure 7 shows the time-dependent change of the difference between the furnace temperature and the minimum temperature of the bearing rings. It can be found that the soaking time of Case1, Case 2 and Case 3 is $11 \mathrm{~min}$, $12 \mathrm{~min}$ and $14 \mathrm{~min}$, which means that the reducing heating rate can help to shorten the soaking time.

Figure 8(a) presents the temperature contours of the bearing rings at the beginning of the soaking stage under different heating rates. It can be seen that the maximum temperature appears on the top corner workpiece, and the minimum temperature appears on the center workpiece. This is because the center workpiece is blocked by the upper and lower workpiece, which is not conducive to absorbing the thermal radiation from the heaters. Figure $8(\mathrm{~b})$ illustrates the maximum temperature difference of the bearing rings. As the heating rate increases from $4^{\circ} \mathrm{C} / \mathrm{min}$ to $10^{\circ} \mathrm{C} / \mathrm{min}$, the maximum temperature difference increases from $20^{\circ} \mathrm{C}$ to $59^{\circ} \mathrm{C}$, which is nearly three times the original.

Temperature uniformity of the workpieces during heating can be evaluated by the standard temperature uniformity index. ${ }^{29)}$ It is expressed as follows:

$$
\text { STUI }=\frac{\int_{V} \sqrt{\left(T-T_{\text {ave }}\right)^{2}} d V}{\int_{V} \sqrt{\left(T_{0}-T_{\text {ave }}\right)^{2}} d V}
$$

where $V$ is the volume of the workpieces; $T$ is the local 

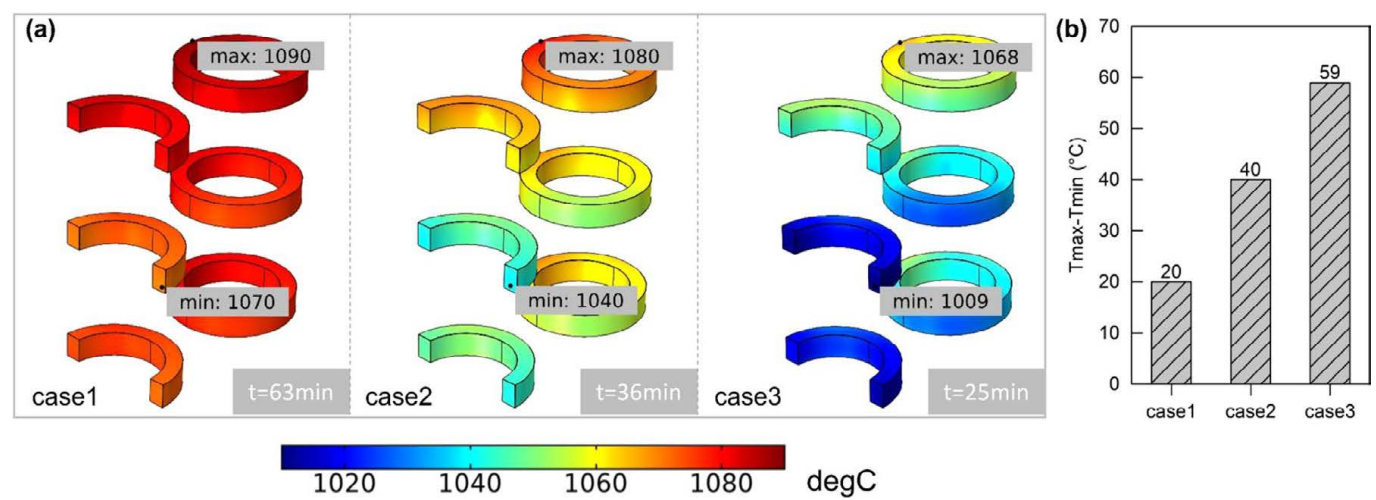

Fig. 8. (a) Temperature field cloud and (b) temperature difference of bearing rings under different heating rates. (Online version in color.)

temperature over the volume; $T_{\text {ave }}$ is the average temperature over the volume; $T_{0}$ is the and the initial uniform temperature of the workpieces. According to the definition, a lower STUI indicates a higher temperature uniformity over the volume.

Figure 9 shows a comparison of the STUI change with time during the soaking stage between Case1, Case2, and Case3. It is clear that the STUI increases with the increase of heating rate and decreases with the extension of soaking time. This indicates that higher heating uniformity can be obtained by reducing the heating rate. However, STUI decreases more slowly as the heating rate decreases. The reason is that the radiation heat flux is proportional to the difference of the fourth power of temperature, but the temperature difference between the furnace and the workpiece is smaller when the heating rate is lower.

\subsection{Effect of Preheating Temperature}

In this section, the effect of preheating temperature on the heating uniformity and the soaking time of bearing ring heating in a vacuum furnace is studied. The heating process parameters are listed in Table 3. Figure $\mathbf{1 0}$ shows the temporal variation of the difference between the furnace temperature and the minimum temperature of the bearing rings under different preheating temperature. It can be found that increasing the preheating temperature can effectively reduce the temperature difference between the furnace and the bearing rings. From the date of Fig. 9, the start time $t_{\mathrm{s}}$ of soaking stage in Case4, Case 5 and Case 6 are the same time, but the end time $t_{\mathrm{e}}$ is different. When the preheating temperature increases from $950^{\circ} \mathrm{C}$ to $1100^{\circ} \mathrm{C}$, the soaking time is shortened from $14 \mathrm{~min}$ to $10 \mathrm{~min}$, about $28 \%$. This indicates that high temperature preheating has great potential for shortening the soaking time.

The temperature counters and the maximum temperature difference of bearing rings at the start of soaking period are shown in Fig. 11. As seen in Fig. 11(a), when the preheating temperature increases from $950^{\circ} \mathrm{C}$ to $1050^{\circ} \mathrm{C}$, the minimum temperature of the bearing rings increases by $21^{\circ} \mathrm{C}$, while the maximum temperature only increases by $2^{\circ} \mathrm{C}$. The maximum temperature difference decreases by $50 \%$ from $35^{\circ} \mathrm{C}$ to $17^{\circ} \mathrm{C}$, as shown in Fig. 11(b). This indicates that preheating can improve temperature uniformity, and the effect becomes more pronounced as the temperature rises.

Figure 12 shows a comparison of the STUI change with time at the soaking stage between Case4, Case 5 and Case6.

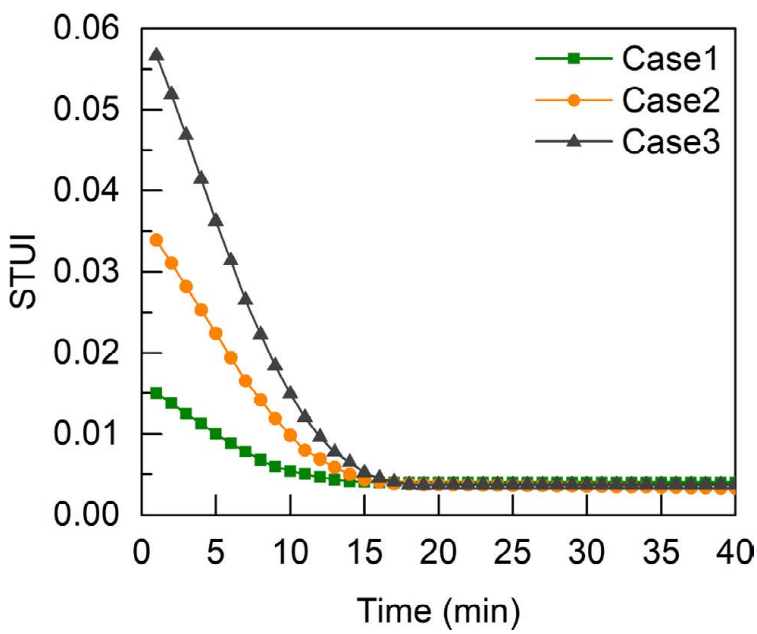

Fig. 9. Change of STUI with time under different heating rates. (Online version in color.)

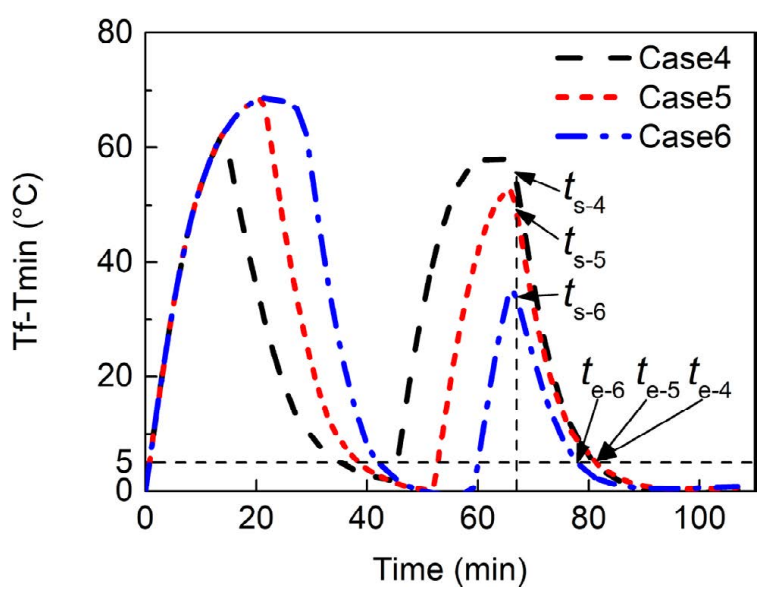

Fig. 10. Temperature difference between the bearing ring and the furnace under different preheating temperature. (Online version in color.)

It can be found that preheating at $1050^{\circ} \mathrm{C}$ can significantly improve the temperature uniformity, and that advantage is maintained throughout the soaking stage.

\subsection{Optimization for Heating Schedule and Effect Test}

In order to obtain high hardness and high wear resistance on the surface of bearing ring, high-pressure gas quenching treatment is carried on the carburized bearing ring in an aviation bearing manufacturing enterprise. However, the 

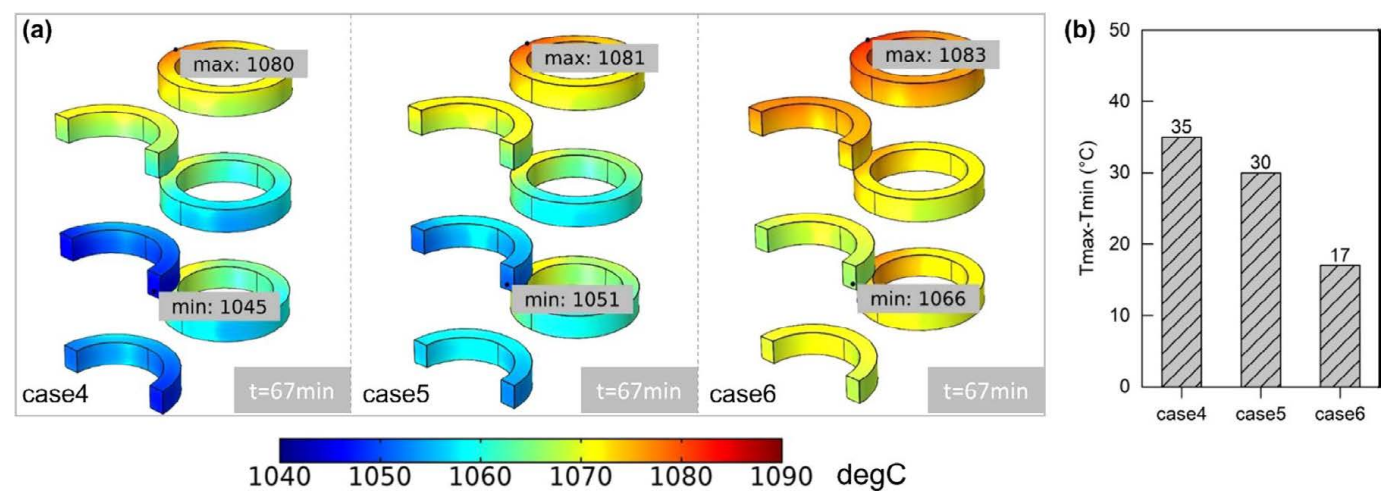

Fig. 11. (a) Temperature field cloud and (b) temperature difference of bearing rings under different preheating temperature. (Online version in color.)

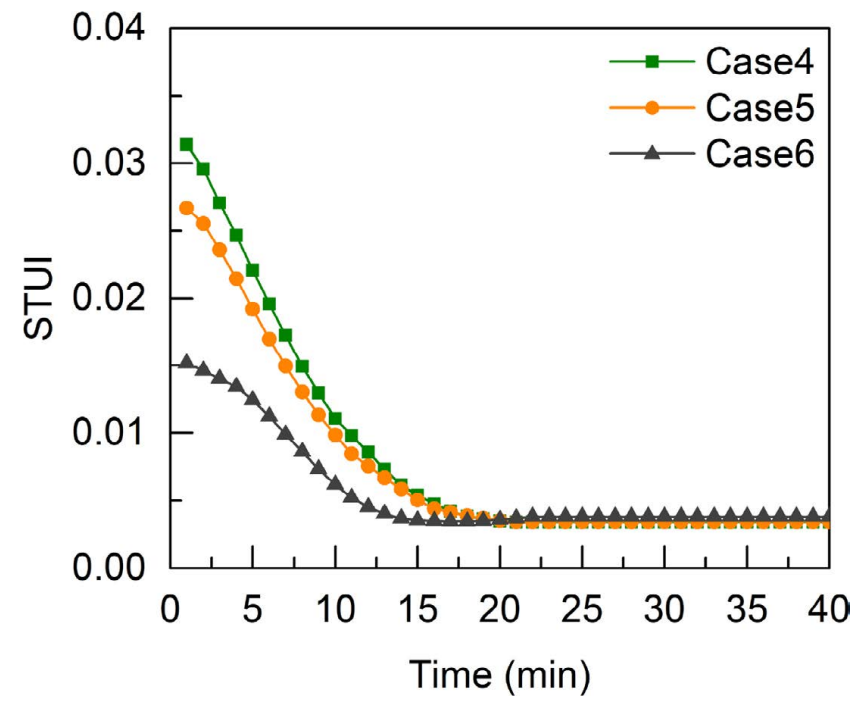

Fig. 12. Changes of STUI with time under different preheating temperature. (Online version in color.)

grain size of the quenched bearing ring is too large to meet the technical requirements. The austenite grains of $\mathrm{M} 50 \mathrm{NiL}$ steel grow slowly at $1050^{\circ} \mathrm{C}$, grow fast at $1100^{\circ} \mathrm{C}$, especially after holding at $1100^{\circ} \mathrm{C}$ for more than $30 \mathrm{~min}^{4)}$ Therefore, shortening the holding time at $1100^{\circ} \mathrm{C}$ will help to prevent the excessive growth of austenite grain. Finally, based on analysis of the above research, this paper gives an optimized heating process, as shown in Fig. 13.

Figure 14 shows the temporal variation of the maximum temperature difference between the bearing rings and the furnace before and after optimization. From the data of Fig. 14 , it can be found that the soaking time of bearing ring is reduced by a quarter from 12 min to 9 min by the optimized heating process. So, while the new process reduces the holding time from $40 \mathrm{~min}$ to $20 \mathrm{~min}$, there is still $11 \mathrm{~min}$ to complete the microstructure transformation.

Figure 15(a) shows the austenite grain morphologies of M50NiL steel heated by the original and optimized process. It can be found that the optimum heating process can successfully prevent overgrowth of austenite grains compared with the original one. The austenite grain size of the samples of the two processes was measured from several optical micrographs using Image-Pro Plus 6.0 software according to ASTM E112-13 (2013), ${ }^{30)}$ as shown in Fig. 15(b). The enterprise standard requires that the grain size is grade 5

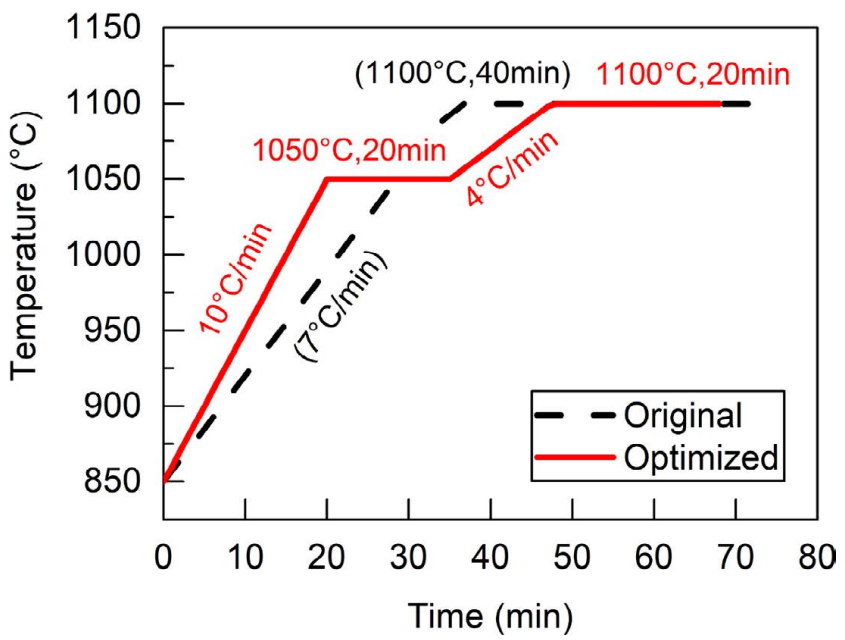

Fig. 13. Original and optimized heating schedule. (Online version in color.)

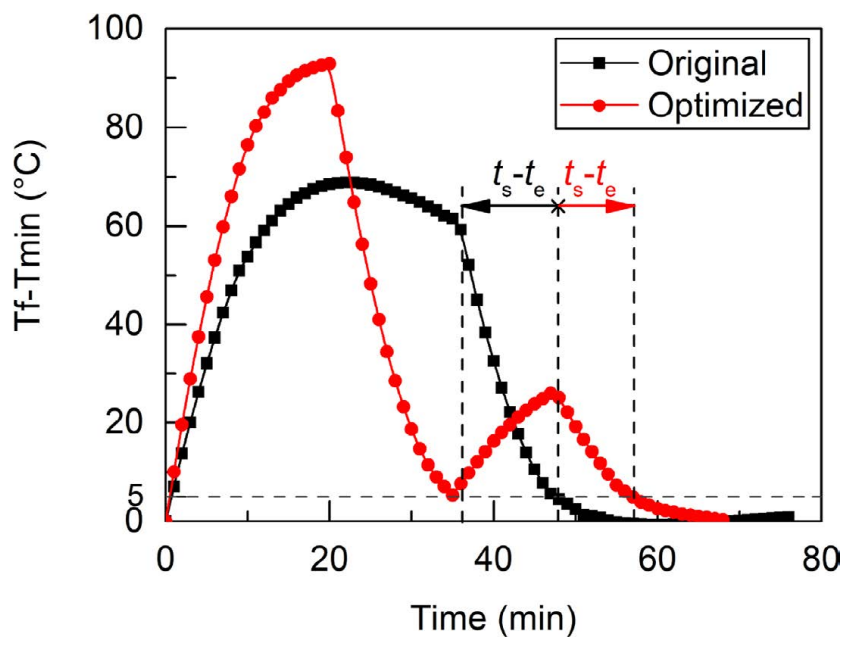

Fig. 14. Temperature difference between the bearing ring and the furnace before and after optimization. (Online version in color.)

or finer, and less than $10 \%$ of grade 3 grains are allowed. From the data of Fig. 15(b), it can be found that the average austenite grain size upgraded from level 5 to level 5.5, and the proportion of grade 3 and coarser grains was reduced from $12 \%$ to $2 \%$. 
(a)

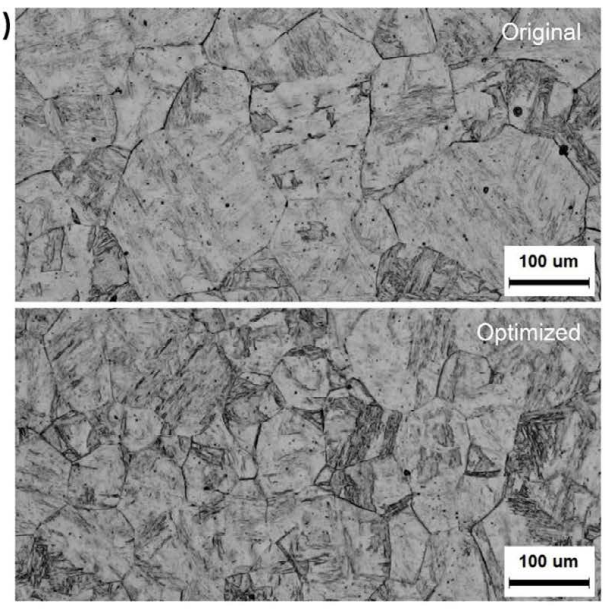

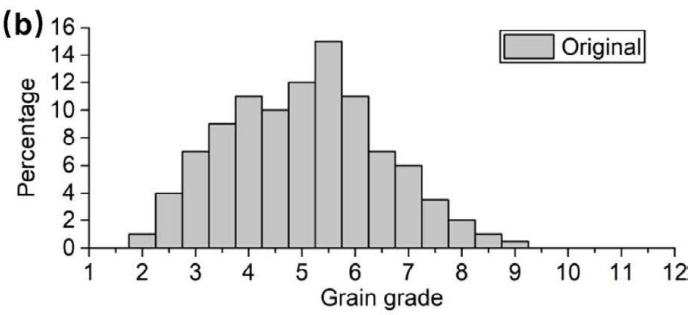

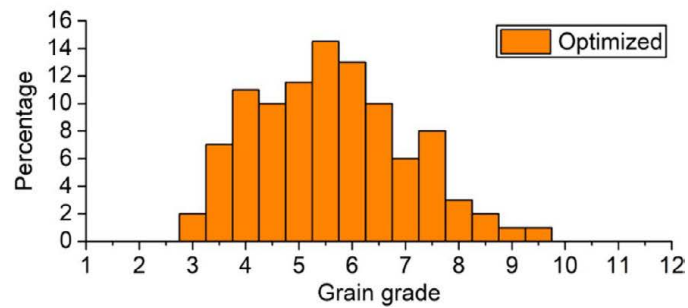

Fig. 15. (a) Morphology and (b) size of the austenite grain of typical samples treated with the original and optimized heating process. (Online version in color.)

\section{Conclusions}

The finite element simulation and analysis of bearing rings heating in a vacuum furnace have been performed with Surface-to-Surface Radiation interface of COMSOL Multiphysics software. The influences of heating rate and preheating temperature on the heating uniformity and soaking time are investigated, and the method to avoid excessive growth of austenite grains is found. The main conclusions are summarized as follows:

(1) The reliability of the numerical model has been verified through experiment. The maximum absolute error between the simulated value and the measured value of the bearing ring temperature is less than $0.6 \%$.

(2) The analysis results show that the standard temperature uniformity index STUI increased with the heating rate and decreased with preheating temperature. It can also find that the soaking time can be shortened by decreasing the heating rate or increasing the preheating temperature.

(3) The proposed optimum heating process with preheating at $1050^{\circ} \mathrm{C}$ and heating at $4^{\circ} \mathrm{C} / \mathrm{min}$ can reduce the soaking time by $25 \%$. Moreover, the new heating process upgraded the average austenite grain size from level 5 to level 5.5 and reduced the proportion of grade 3 and coarser grains from $12 \%$ to $2 \%$.

\section{Acknowledgement}

This work was supported by the Fundamental Research Funds for the Central Universities (Program No. N2007005).

\section{REFERENCES}

1) G. M. Li, Y . L. Liang, C. H. Yin, H. Sun and Z, L. Zhu: Surf. Coat. Technol., 375 (2019), 132. https://doi.org/10.1016/j. surfcoat.2019.07.017

2) H. Bhadeshia: Prog. Mater. Sci., 57 (2012), 268. https://doi. org/10.1016/j.pmatsci.2011.06.002

3) S. Ooi and H. Bhadeshia: ISIJ Int., 52 (2012), 1927. https://doi. org/10.2355/isijinternational.52.1927

4) X. Yang, J. Lan and H. Huang: Heat Treat. Met., 43 (2018), 105 (in Chinese). https://doi.org/10.13251/j.issn.0254-6051.2018.12.020

5) K. Y. Ding, L. Li, G. L. Ji and Q. Li: Trans. Mater. Heat Treat., 37 (2016), 166 (in Chinese). https://doi.org/10.13289/j.issn.10096264.2016 .11 .028
6) H. Qiu, T. Hanamura and S. Torizuka: ISIJ Int., 54 (2014), 1958. https://doi.org/10.2355/isijinternational.54.1958

7) X. D. Li, X. P. Ma, S. V. Subramanian, C. J. Shang and R. D. K. Misra: Mater. Sci. Eng. A, 616 (2014), 141. https://doi.org/10.1016/j. msea.2014.07.100

8) G. Liu, S. Winwood, K. Rhodes and S. Birosca: Int. J. Plast., 125 (2020), 150. https://doi.org/10.1016/j.ijplas.2019.09.010

9) D. H. Herring: Ind. Heat., 75 (2008), 57.

10) É. N. Marmer: Chem. Pet. Eng., 18 (1982), 287. https://doi. org/10.1007/BF01230108

11) R. Atraszkiewicz, B. Januszewicz, Ł. Kaczmarek, W. Stachurski, K. Dybowski and A. Rzepkowski: Mater. Sci. Eng. A, 558 (2012), 550. https://doi.org/10.1016/j.msea.2012.08.047

12) W. L. Xue, S. Gao, Y. Wang, H. P. Hou and J. H. Wang: Heat Treat. Met., 44 (2019), 13 (in Chinese). https://doi.org/10.13251/j.issn.02546051.2019.01.003

13) X. W. Hao, J. F. Gu, N. L. Chen, W. M. Zhang and X. W. Zuo: Appl. Therm. Eng., 28 (2008), 1925. https://doi.org/10.1016/j. applthermaleng.2007.12.007

14) J. R. Howell, M. P. Mengüç and R. Siegel: Thermal Radiation Heat Transfer, 6th ed., Taylor \& Francis, New York, (2016), 619.

15) Y. Sun and X. Zhang: Numer. Heat Transf., Part A, 68 (2015), 619. https://doi.org/10.1080/10407782.2014.994406

16) Y. Sun, X. Zhang and J. R. Howell: J. Quant. Spectrosc. Radiat. Transf., 184 (2016), 262. https://doi.org/10.1016/j.jqsrt.2016.07.024

17) M. N. Borjini, H. Farhat and M. S. Radhouani: Numer. Heat Transf., Part A, 44 (2003), 199. https://doi.org/10.1080/713838192

18) K. Lari and S. A. G. Nassab: Therm. Sci., 16 (2012), 1187. https:// doi.org/10.2298/TSCI110121034L

19) B. Mayr, R. Prieler, M. Demuth and C. Hochenauer: Appl. Therm. Eng., 127 (2017), 679. https://doi.org/10.1016/j.applthermaleng.2017.08.054

20) H. Yuki: Tetsu-to-Hagané, 104 (2018), 699 (in Japanese). https://doi. org/10.2355/tetsutohagane.TETSU-2018-065

21) M. Y. Gu, G. Chen, X. H. Liu, C. C. Wua and H. Q. Chu: Int. J. Heat Mass Transf., 76 (2014), 405. https://doi.org/10.1016/j. ijheatmasstransfer.2014.04.061

22) Y. J. Liu, J. D. Li, R. D. K. Misra, Z. D. Wang and G. D. Wang: Appl. Therm. Eng., 107 (2016), 1304. https://doi.org/10.1016/j. applthermaleng.2016.07.074

23) H. Ramezanzadeh, A. Ramiar and M. Yousefifard: Appl. Therm. Eng., 122 (2017), 253. https://doi.org/10.1016/j.applthermaleng.2017.05.008

24) X. Dong and X. M. Liu: Heat Transf., Part A, 77 (2020), 90. https:// doi.org/10.1080/10407782.2019.1682872

25) F. Tikal, M. Duchek and J. Nacházel: Appl. Mech. Mater., 751 (2015), 235. https://doi.org/10.4028/www.scientific.net/AMM.751.235

26) M. B. Turgay and A. G. Yazıcığlu: Heat Transf., Part A, 73 (2018), 332. https://doi.org/10.1080/10407782.2017.1420302

27) COMSOL Inc.: COMSOL Multiphysics User's Guide, Version 5.4, (2018), https://doc.comsol.com/5.4/doc/com.comsol.help.comsol/ COMSOL_ReferenceManual.pdf, (accessed 2019-6-14).

28) S. Q. Zhang: Heat Treat. Met., 1 (2000), 38. https://doi.org/10.3969/j. issn.0254-6051.2000.01.014

29) H. Ramezanzadeh, A. Ramiar and M. Yousefifard: Appl. Therm. Eng., 122 (2017), 253. https://doi.org/10.1016/j.applthermaleng.2017.05.008

30) ASTM E112-13: 2015, Standard test method for determining average grain size. 